\title{
Segurança humana, direitos e políticas públicas ${ }^{1^{*}}$
}

\author{
Human security, rights and public policies
}

\author{
JesÚS BALLESTEROS ${ }^{2 * *}$ \\ Catedrático de Filosofia do Direito na Universidade de Valência (Espanha) \\ Tradução: \\ ALFREDO DE J. FLORES \\ PPGDir/UFRGS
}

\begin{abstract}
RESUMO: Neste trabalho, o autor defende o enfoque amplo da doutrina da segurança humana que é propugnado pelo Japão e pelas Nações Unidas, segundo o qual se deve atender conjuntamente à freedom from fear e à freedom from want, contrariamente ao enfoque restrito, defendido por Canadá, Noruega e a Rede de Segurança Humana, que se limita à luta contra as guerras. A razão de dita opção se deve ao fato de que as condições de miséria (desnutrição, falta de água potável e de medicamentos) produzem um número muito maior de mortes evitáveis anuais que a realidade das guerras. Da mesma forma, criar condições dignas de vida é o melhor modo de conseguir a paz.
\end{abstract}

Palavras-chave: Segurança humana; Políticas públicas; Cultura de paz; Direitos humanos.

\begin{abstract}
In this paper, the author defends the broad focus of the doctrine of human security that is advocated by Japan and the United Nations, and, according to that, it should attend both "freedom from fear" and "freedom from want", unlike the narrow focus, defended by Canada, Norway and Human Security Network, that is limited to fight against wars. That option is due to the fact that the extreme poverty (malnutrition, lack of clean water and medicines) produce a much larger number of preventable deaths annually than the reality of war. Likewise, create decent living conditions is the best way to achieve peace.
\end{abstract}

Keywords: Human security; Public policy; Culture of peace; Human rights.

\section{SEGURANÇA HUMANA, PRIORIDADE DAS PESSOAS E NÃO-VIOLÊNCIA. INDO ALÉM DA SEGURANÇA NACIONAL}

Desde a criação do Estado moderno até a queda do bloco comunista, a ideia de segurança se vinculava à noção de soberania nacional, a qual implica a legitimidade do uso exclusivo da força tanto no âmbito interno, ao defender os cidadãos ante a violência dos outros cidadãos (ordem pública), como no externo, ao defender o território nacional frente a agressões de outros Estados. A chave da segurança nacional estava fundada no poder das armas.

A novidade que introduz a doutrina da segurança humana não se opõe, em princípio, ao monopólio da força em mãos do Estado, já que a ausência de tal monopólio, como ocorre nos Estados em crise (failed States), é a causa de graves danos às pessoas e de um grande número de mortes evitáveis pela atuação incontrolada dos grupos paramilitares ou associações delitivas. A mudança no conceito de segurança, introduzida pela doutrina da segurança humana, está radicada de forma simultânea nos seguintes aspectos: a) na passagem de um enfoque "macro", centrado no Estado, a um enfoque "micro", centrado na pessoa; b) no alargamento do conceito mesmo de segurança, compreendendo não somente as ameaças provenientes do exterior, mas também as que vêm do próprio Estado (de fato, nos últimos cem anos, a maior parte das pessoas foi assassinada por seus próprios governos e não por governos estrangeiros) - não somente as ameaças violentas (hard threats), mas também as aparentemente não violentas (soft threats), que causam mortes evitáveis, por falta de alimentos e remédios.

Todos os defensores da doutrina da segurança humana coincidem em que o objetivo primário consiste na proteção dos indivíduos, e não no aumento de armas. Nesse sentido, dois estudos recentes, entre muitos outros, ressaltam essa diferença entre a ideia de segurança nacional e a de segurança humana. Assim, 
o Parecer sobre uma estratégia de segurança humana para a União Europeia, dirigido por Mary Kaldor e Marlies Glasius, destaca que "a primazia dos direitos humanos é o que distingue o conceito de segurança humana do conceito de segurança nacional". Por sua vez, no parecer da Anistia Internacional de 2006. Em busca da segurança humana, afirma-se que "o que caracteriza a segurança humana é a convicção de que não se pode perseguir a segurança violando os direitos humanos", pois a "verdadeira segurança humana consiste em fazer os direitos humanos efetivos a todos".

O consenso entre os defensores da doutrina da segurança humana vem menos com relação à individuação do tipo de ameaças, das quais o indivíduo deve ser defendido. De fato, alguns sustentam a exclusão da violência, enquanto que outros, a exclusão da pobreza. Os primeiros destacam a relação da segurança com a defesa; os segundos, a relação existente entre segurança e desenvolvimento.

A primeira corrente doutrinal é aquela canadense, tal como foi proposta pelo Ministro de Relações Exteriores, Axworthy, em 1996, baseando-se na superação da violência nas relações internacionais e, por conseguinte, na superação do paradigma da segurança nacional. Tal visão entende substituir a velha diplomacia que apela às armas, i.e. a prática do bastão largo (big stick), proposta por Theodor Roosevelt e por muitos de seus sucessores na Casa Branca, por uma nova diplomacia fundada no soft power, no poder de persuasão. Dado que a teoria da dissuasão do "si vis pacem, para bellum" não conseguiu que houvesse um só dia no mundo sem guerra, essa deve ser repensada de acordo com o critério muito mais razoável, do " $s i$ vis pacem, para pacem". Em consequência, segundo Axworthy, o poderio militar tem uma utilidade pacífica decrescente na política mundial e o Estado deve seguir o modelo das ONGs, segundo o qual o Canadá é líder da coalizão de todos aqueles que são dispostos, os voluntários (coalitions of the willing ${ }^{3,4}$ ).

Essas eventuais coalitions of the willing não devem ser confundidas com a coalition formada pelos Estados Unidos para invadir o Iraque, o que o Canadá rechaçou de forma expressa. Precisamente a invasão do Iraque, na medida em que pôde ser disfarçada como uma operação em favor da segurança humana pelo Departamento de Segurança Pátria (Homeland Security) dos Estados Unidos, causou um gravíssimo prejuízo a esse conceito. $\mathrm{O}$ excelente documento do Programa de Desenvolvimento das Nações Unidas, o "The Human Security Framework and the National Human Development Reports" de 2006, coordenado por Richard Jolly e Deepayan Basu Ray ${ }^{5}$, constitui uma resposta contundente às diversas objeções formuladas ao conceito de segurança humana.

Ainda que o programa inicial de Axworthy compreendesse também a total eliminação das mortes evitáveis como aquelas geradas pela fome e pelas epidemias, a política exterior do Canadá terminou propondo uma tese restritiva (narrow) de segurança como proteção da liberdade, entendida exclusivamente como freedom from fear, ante a violência física, no caso de conflito. Para interromper o círculo de violência, caberia recorrer às intervenções humanitárias, mediante uma força civil de paz (peacemaking) de caráter multilateral que assegurasse a liberdade de imprensa e a existência de um Poder judiciário independente.

Por sua vez, o Canadá promoveu em 2001 a criação da Comissão Internacional sobre Intervenção e Soberania Estatal (CISSE ou ICISS), para cumprir para com os Objetivos do Milênio, dentre os quais, de modo particular, a defesa da democracia e da não-violência. Essa Comissão fez a redação de um parecer substituindo a tese do direito a intervir pela da "responsabilidade de proteger" (responsability to protect), no sentido de prevenir, atuar e reconstruir.

Apesar da importância desta mudança de enfoque, subsiste o risco de servir de instrumento da agenda neoliberal do Norte para impor os seus próprios valores aos países do Sul, incrementando o perigo de intervenção militar em tal zona. Por outro lado, essa mesma redução da segurança humana a somente questões relacionadas à eliminação da violência oferece um enfoque conservador e pouco crítico das relações internacionais, sustentando posições que se consideram satisfeitas somente com a redução do número de guerras no mundo, tal como ressalta o último Human security Report. Esse caráter conservador é maior no caso da adesão do Canadá ao assim chamado "Consenso de Washington", que aceita a desregulamentação da economia, favorecendo as desigualdades econômicas no mundo ${ }^{6}$. Assim também a assinatura do acordo de defesa com os Estados Unidos em 09 de dezembro de 2001, que Axworthy qualificou como o fim da soberania canadense $\mathrm{T}^{7}$.

$\mathrm{O}$ aspecto mais positivo do enfoque canadense consistiu no impulsionar a estipulação de acordos contra as minas pessoais e a criação do Tribunal Penal Internacional, assim como a Rede de Segurança Humana, em 1998, sob a tutela do Canadá e da Noruega. Essa rede reúne vários países europeus de dimensão média ou pequena (Áustria, Holanda, Eslovênia, Suíça), como também países da América (como o Chile) e asiáticos (como Tailândia e Jordânia), incluindo entre os seus objetivos não somente a proteção contra a violência e a defesa da democracia (entendida 
essa como o "bom governo", com a obrigação de prestar contas), mas também a educação em direitos humanos, a luta contra a pobreza absoluta e em favor do desenvolvimento sustentável ${ }^{8}$ e a proteção em caso de crises financeiras, contaminação e conflitos laborais.

\section{SEGURANÇA HUMANA COMO ESPECIFICAÇÃODO DESENVOLVIMENTO HUMANO EM SITUAÇÕES DE ESPECIAL VULNERABILIDADE}

Enquanto o conceito de segurança humana, na sua acepção restrita, tem como ponto de referência a superação da noção de segurança nacional, a acepção mais ampla de segurança humana se refere à superação do conceito de desenvolvimento como Produto Interno Bruto e a sua substituição pelo conceito de desenvolvimento humano.

Este enfoque se funda na consciência do caráter imprescindível dos dois conceitos de desenvolvimento (com a inseparabilidade da realidade da segurança e do desenvolvimento ${ }^{9}$ ), superando a tradicional concepção do desenvolvimento entendido como mero crescimento econômico (no sentido economicista ${ }^{10}$ ), em favor de insistir na responsabilidade para com o desenvolvimento ("responsability for development"). A coincidência destas duas realidades explica o fato de que a noção de segurança humana apareça precisamente no Parecer sobre o Desenvolvimento Humano de 1994. Tal teoria, fundada na centralidade do ser humano e na potencialização das próprias capacidades, aparece como um novo paradigma das políticas públicas. Como disse Des Gasper, seguindo a Asunción Lera St. Clair, "o discurso sobre a segurança humana é um discurso para estabelecer prioridades no âmbito político" 11,12 . De fato, tal conceito surge em 1994 por ocasião da organização da Conferência de Copenhague sobre o assim dito "dividendo de paz" no Programa das Nações Unidas para o Desenvolvimento Humano, sendo desenvolvido na atualidade na Comissão de Segurança Humana, criada em 2003 e liderada por Japão, com apoio do Chile.

Essa concepção entender que se deve distinguir o conceito de segurança humana daquele de desenvolvimento humano, tal como se faz no Parecer sobre o Desenvolvimento Humano de $1994^{13}$, afirmando que o desenvolvimento humano é equivalente ao "processo de expansão das liberdades reais que desfrutam as pessoas".

O conceito de desenvolvimento humano, sustentado pelas Nações Unidas, inspira-se no conceito de "capabilities" (capacidades) de Amartya Sen, sendo que este é precisamente coautor daquele conceito, enquanto copresidente, com Osako Ogata, da Comissão de Segurança Humana. Segundo esse mesmo conceito, deve-se considerar que o que limita o desenvolvimento humano não seria somente o baixo nível de renda, mas também a falta de acesso à educação básica e à assistência sanitária adequada ${ }^{14}$.

Amartya $\operatorname{Sen}^{15}$ escreve que a segurança humana pode ser entendida como a proteção e a preservação da sobrevivência humana e da vida quotidiana (contra as mortes prematuras, as enfermidades evitáveis, a incapacidade do analfabetismo), assim como a eliminação de várias indignidades que podem provocar dano, ofensa ou desprezo em nossas vidas, como, por exemplo, a indigência, a penúria, o encarceramento, a exclusão e o analfabetismo. De fato, esse parecer fala de segurança com relação às ameaças crônicas, como a fome, a doença evitável e a repressão, e ainda da proteção ante as interrupções súbitas e danosas dos modelos de vida ordinária, tanto no trabalho, família ou comunidades. "O desenvolvimento humano implica uma noção sumamente positiva, a do crescimento com equidade. A segurança humana une uma dimensão humana ao conceito de desenvolvimento, sublinhando a exigência de garantir o desenvolvimento em situações de crises repentinas e inesperadas, em situações arriscadas e desfavoráveis", os downside risks (termo curiosamente procedente da economia das bolsas). Des Gasper ${ }^{16,17}$ assinala que tal conceito se distingue daquele de human development, por seu caráter de urgência, de prioridade total na política, por sua exigência de implementation $^{18}$ (implementação), de efetividade e por seu sentido de concreção, na luta contra as vulnerabilidades físicas evitáveis. Isso exige a razão cordial, o sentimento compartido, não somente a compreensão compartida. Trata-se de administrar os riscos dos mais necessitados. $\mathrm{O}$ conceito de segurança humana parte, como se pode ver, da dimensão da necessidade do ser humano (contra a monstruosidade ${ }^{19}$ e o malquerer de alguns), e ressalta como prioridade mundial a luta contra as vulnerabilidades ou fragilidades físicas evitáveis ${ }^{20}$.

A noção de segurança humana se caracteriza pela exigência de desenvolvimento em situações de especial vulnerabilidade, nas "emergências políticas complexas", que são provocadas fundamentalmente por perdas econômicas ou crises estatais que geram conflitos especialmente dentro do Estado, ou dão lugar a guerras especialmente entre $\operatorname{Estados}^{21}$, bem como doenças, fomes e migrações, insalubridade, analfabetismo e ditaduras.

O Parecer sobre o Desenvolvimento Humano de 1994, em que aparece por primeira vez o conceito de segurança humana, faz referência a sete tipos de segurança humana, sendo que os quatro primeiros estão 
relacionados entre si e com a liberação da necessidade, como a segurança econômica (incluindo o acesso ao emprego e aos meios necessários para o sustento), a segurança alimentar, a segurança da saúde, a segurança ecológica ${ }^{22}$.

Um dado impressionante: "Nos países em via de desenvolvimento, as principais causas de morte são as doenças contagiosas e parasitárias, que matam 17 milhões de pessoas por ano. Nesse sentido, perdem a vida 6.5 milhões de pessoas devido a infecções respiratórias agudas; 4.5 milhões devido a doenças diarreicas; e 3.5 milhões por causa da tuberculose. A maioria destas doenças é causada pela desnutrição e um ambiente insalubre, sobretudo pelo abastecimento de água contaminada que contribui para gerar cerca de 1 bilhão de casos de diarreia ao ano".

Os três últimos tipos de segurança humana, por outro lado, são relacionados à liberação pelo medo. Trata-se da segurança pessoal frente às ameaças à integridade física provenientes seja do próprio Estado (como a tortura física), seja de outros Estados (como a guerra), ou ainda de outros grupos (como a violência étnica), ou de outros indivíduos particulares (violência de rua), contra as mulheres (violação, violência doméstica) e contra as crianças. O Parecer sobre o Desenvolvimento Humano de 1994 refere, por fim, à segurança da comunidade ante as agressões recebidas dentro do próprio grupo (como a violência doméstica), e a segurança política ante o despotismo.

Em favor de uma noção ampla de segurança humana, manifesta-se também o Primeiro Ministro japonês, Obuchi Keizo, principal promotor da Comissão de Segurança Humana ${ }^{23,24}$ ao defini-la como "apreensão integral de tudo que possa atentar contra a sobrevivência, a vida quotidiana e a dignidade dos seres humanos e o fortalecimento dos esforços para fazer frente a essas ameaças". No Parecer da citada Comissão, feito público em 2003, define-se a segurança humana como "proteção do núcleo vital de todas as vidas humanas com o fim de aumentar as liberdades e a autorrealização humana ${ }^{25}$. A segurança humana significa proteger as liberdades humanas, que são a essência da vida, das ameaças agudas (critical) e persistentes (persuasive). O núcleo vital é constituído pelo conjunto dos direitos humanos e pelas liberdades que desfrutam as pessoas. $\mathrm{O}$ que se considera vital varia segundo indivíduos e sociedades. Por isso, o conceito de segurança humana deve ser dinâmico e não se propõe uma lista detalhada do que constitui a segurança humana" (p. 4).

No parecer se destacam seis situações de especial vulnerabilidade, que devem ser tidas em conta na hora de defender a segurança humana:
1. A proteção dos civis, especialmente mulheres, crianças, anciãos e incapacitados em situação de conflito. A Comissão apoia as iniciativas destinadas a combater a proliferação de armas de grande e pequena dimensão.

2. A situação das pessoas em situação de trânsito, como os deslocados dentro de um Estado, os refugiados e os imigrantes. Quanto a estes últimos, a Comissão sugere o estabelecimento de um marco normativo, que ainda não existe, e de medidas práticas para equilibrar os interesses legítimos dos Estados e a proteção dos imigrantes;

3. Os momentos de transição entre guerra e paz. O desafio de reconstruir sociedades destroçadas demanda uma concentração dos meios institucionais e financeiros para gerir do modo mais eficiente possível os vários elementos destinados a garantir a segurança das pessoas e das comunidades com o objetivo de alcançar uma paz duradoura. A responsabilidade de proteger as pessoas em situações de conflito se completa mediante a responsabilidade pela reconstrução;

4. A exigência de assegurar um mínimo nível de vida econômica, superando a miséria, a fome, a falta de acesso à água potável. Mesmo reconhecendo o valor dos mercados, requer-se uma adequada distribuição dos benefícios do crescimento, como os acordos comerciais eficientes e equitativos. Três quartos da humanidade não goza de proteção da segurança social ou não tem um trabalho garantido. É preciso lutar pelo pleno emprego e garantir o acesso à terra, ao crédito, à educação e à casa própria, especialmente para as mulheres pobres. A miséria, chamada equivocadamente de "pobreza absoluta", está na origem de doenças contagiosas (AIDS, malária, Mal de Chagas), que causam o maior número de mortes evitáveis ${ }^{26}$.

5. O acesso universal a condições sanitárias e aos serviços básicos de saúde pública, assim como a produtos farmacêuticos necessários para poder lutar contra as doenças que impliquem em risco de morte. É necessário estabelecer uma regulamentação equitativa dos direitos de propriedade intelectual, que permita um equilíbrio entre os incentivos para a pesquisa e o acesso à cura por medicamentos para os mais pobres. Em 2001, 22 milhões de pessoas morreram por doenças evitáveis.

6. O acesso à instrução elementar a todos, especialmente para as meninas, o que constitui uma prioridade absoluta para cumprir com a agenda de empenhos da Comissão. O conteúdo da educação é sumamente importante e serve para impedir a propagação do ódio e da discriminação. O papel 
da escola é esclarecer a necessidade de uma identidade humana global, respeitando, por sua vez, a liberdade dos indivíduos de ter diversas identidades e afiliações. Com relação à educação, é fundamental que todo ser humano tenha consciência de seus direitos e dos modos de fazê-los efetivos.

Por isso, a presidente da Rede pela Segurança humana, Benita Ferrero-Waldner, em 2003, promoveu a redação do livro Compreendendo os direitos humanos, onde se apresentam os quatro tipos de segurança humana: a segurança pessoal, possível por meio do reconhecimento das garantias processuais; a segurança social, por meio da satisfação das necessidades básicas, como a segurança alimentar e a assistência sanitária; a segurança internacional (ou direito a viver numa ordem internacional segura, que preveja os conflitos); e a segurança democrática e aquela educativa ${ }^{27}$.

De sua parte, o parecer da Conferência de Helsinki de 2004, Empowering people at risk: Human Security priorities for the 21 Century, coordenado por Hampson, destaca essas cinco prioridades: saúde; tráfico de seres humanos; violência contra as mulheres; crianças envolvidas em conflitos armados; e proibição de armas ligeiras.

Ademais, Gary King e Ch. Murray ${ }^{28}$ deram uma importante contribuição para precisar o conceito de segurança humana tratando de quantificar e materializar o enfoque de A. Sen. Para isso, parte-se do conceito de "pobreza generalizada", que vai além da pobreza de renda, ainda que resulte, segundo eles, em algo mensurável. Assim, deve-se falar de pobreza generalizada com relação à renda quando é inferior a um dólar; quanto à saúde, quando é somente algo superior à tetraplegia (é o conceito que ficou mais ambíguo); com relação à educação, quando fica abaixo da alfabetização; quanto à democracia, quando não se reconhece o sufrágio universal. Para alcançar efetividade nas políticas públicas, consideram que se deve dar prioridade ao processo de valoração e prevenção de riscos - estudando as causas da violência e da miséria, com atenção à biodiversidade e às crises econômicas - antes que ao processo de proteção e compensação.

\section{SEGURANÇA HUMANA E DIREITOS HUMANOS URGENTES. INDIVISIBILIDADE E PRIORIDADE DOS DIREITOS}

Assim, os conceitos de segurança humana e de direitos humanos estão intimamente relacionados, dado que, como se disse com razão, "a segurança humana é tudo aquilo que se refere aos direitos humanos" 29 . Podese acrescentar que, ainda que nem todos os direitos humanos se refiram à segurança humana, esta pode ser considerada como o núcleo duro ou, pelo menos, o mais urgente de tais direitos, dos quais se destaca a inseparabilidade dos direitos. Essa é a perspectiva de A. Sen ao sublinhar que a segurança humana pode ser considerada uma classe de direitos humanos, que devem dar origem para sua efetividade a "obrigações perfeitas" 30,31 .

Diferentes autores insistiram na recíproca interferência entre o paradigma da segurança humana e a inseparabilidade dos direitos humanos; assim, por exemplo, Sabina Alkire ${ }^{32,33}$ ou Sonia Picado Sotela ${ }^{34}$.

Por sua vez, Alkire destaca como "a inseparabilidade dos direitos é algo que se percebeu no final da Guerra Fria, junto com a aparição dos direitos de terceira geração, e considera que o conceito de segurança humana, enquanto defesa do núcleo vital do homem, segundo se indica no Parecer de 2003, constitui o núcleo central dos direitos humanos. Mas, segundo essa tese, deve-se distinguir entre o conceito de segurança humana e o de direitos humanos". É o que vamos ver na sequência.

Em 1968, a Declaração das Nações Unidas promovida pela Conferência de Teerã, em seu artigo 13, aponta que "tendo em conta que os direitos humanos e as liberdades fundamentais são indivisíveis, a realização dos direitos civis e políticos, sem o gozo dos direitos econômicos, sociais e culturais, resulta impossível. A consecução de um progresso duradouro na realização dos direitos humanos depende de políticas nacionais e internacionais de desenvolvimento econômico e social que sejam boas e eficazes". Analogamente, ao analisar a problemática do desenvolvimento, diferentes autores destacaram essa interdependência e igualdade de nível dos direitos. Nesse sentido, entre outros, A. Sen, Martha Nussbaum ${ }^{35}$, F. Viola ${ }^{36}$, Meyer Bisch ${ }^{37}$ ou E. Fernández Ruiz Gálvez ${ }^{38}$.

A novidade que introduz a problemática da segurança humana é a possibilidade de estabelecer certas prioridades, definindo os objetivos das políticas públicas. Assim, escrevem Senn e Anand: "os defensores dos direitos humanos defendem a indivisibilidade dos direitos e sua igual importância. Essa exigência é válida na medida em que nega a existência de hierarquias entre os particulares tipos de direitos; deve, contudo, ser rechaçada quando entenda definir os objetivos das políticas públicas, já que, dada a escassez de recursos e as obrigações (constraints) institucionais, é necessário que se priorizem alguns direitos". A análise do desenvolvimento humano (e o da segurança humana) nos ajuda a compreender isso claramente $^{39}$. 
O estudo das capabilities (capacidades) supera a teoria dos bens elementares de Rawls, ao ressaltar que a posse de iguais bens jurídicos pode dar lugar a situações jurídicas diversas, segundo as capabilities ${ }^{40}$ do sujeito. O que é importante são a efetividade e a igualdade no gozo das liberdades. Desde este aspecto, a teoria de Rawls é insuficiente e tende a colocar, no mesmo plano, todos os direitos humanos ${ }^{41}$.

Do mesmo modo, o conceito de segurança humana implica a superação do conceito de urgent rights de Rawls, no seu livro The Law of Peoples (em que exclui o direito à participação política e à educação, colocando ainda os direitos das mulheres em outro modelo de "direitos urgentes", compreensivo destes três direitos). Por isso, como já foi sublinhado, é necessário o conceito amplo de segurança humana, como defende a Comissão de Segurança Humana, liderada por Japão.

Trata-se, portanto, também de estabelecer um conteúdo mínimo para os direitos humanos. Podese afirmar uma espécie de "estado de exceção" de significado contraposto ao habitual, já que não se trata de reduzir os direitos, mas sim de garanti-los ante tais situações de emergência. O seu conteúdo é mais amplo e também mais universalista que o de Rawls, uma vez que se discute para além das fronteiras e das disciplinas $^{42}$.

A segurança humana requer empowerment (habilitação, capacitação e, portanto, direitos de participação democrática). É o que sublinhou Sen em seus estudos sobre a escassez de alimentos. Igualmente o Parecer da Comissão de Segurança Humana de 2003, liderada pelo Japão, destaca que "o fomento dos princípios democráticos constitui um passo para a conquista da segurança humana e do desenvolvimento: permite às pessoas participar nas estruturas de governabilidade e fazer que sua voz seja escutada". De sua parte, Caroline Thomas adverte que "a segurança humana está orientada para uma noção ativa e subjetiva da democracia, que possa garantir a todos a oportunidade de participar nas decisões que afetam a suas vidas. Portanto, está relacionada com as discussões sobre a democracia em todos os níveis, desde o local até o global"43. Vai, portanto, além das necessidades básicas materiais ${ }^{4}$. Desta forma, é o próprio conceito de segurança humana que fortalece a democracia, baseando-se na defesa de todas as pessoas, em suas garantias jurisdicionais, na exclusão da tortura e dos maus-tratos.

Sabina Alkire acredita que a distinção entre segurança humana e direitos humanos se fundamenta de mais a mais na exigência de privilegiar determinados direitos nas diversas sedes institucionais, também por intermédio de distintos instrumentos para garantir- lhe a efetividade (i. e., por instituições e meios de fazê-los efetivos ${ }^{45}$ ), posto que, no caso dos direitos, trata-se de estabelecer procedimentos jurídicos para prevenir os abusos dos direitos ou ainda castigar a seus transgressores, enquanto que, no caso da segurança humana, são colocadas em consideração os meios econômicos, políticos ou, inclusive, militares ${ }^{46}$.

Mas esta distinção não parece demasiado relevante enquanto se entenda que tais medidas devem sempre estar conforme ao direito.

Para concluir, o tratamento que distingue da melhor forma a segurança humana do que são os direitos humanos é a exigência de privilegiar a atenção a certos direitos em situações de maior risco quanto à indivisibilidade e igualdade de todos os direitos, rebatida por outro lado pela teoria dos direitos humanos ${ }^{47}$.

\section{EM FAVOR DO CONCEITO AMPLO DE SEGURANÇA HUMANA, COMO ENFOQUE QUE SUPERA O ETNOCENTRISMO E O RELATIVISMO CULTURAL ${ }^{48}$}

O conceito amplo de segurança humana une seguridade e desenvolvimento. Tal conceito entende sublinhar, assim como foi propugnado pelos diversos pareceres das Nações Unidas, desde 2003 ao unir a defesa da freedom from fear e da freedom from want.

As Nações Unidas e o Japão apoiam claramente um conceito amplo de segurança humana, mas negam as intervenções humanitárias com uso da força. Já a Europa, no seu Parecer A Human Security Strategy for the European Union, dirigido por M. Kaldor e M. Glasius, manifesta-se em favor do conceito amplo de segurança humana, como princípio que deve reger a política exterior comum de segurança e desenvolvimento, mas utiliza o conceito mais restrito para justificar o emprego das próprias capacidades operativas, sem, por isso, ter de pressupor uma intervenção com limitação da soberania (p. 67 et seq.).

As razões em favor do caráter amplo da segurança humana, unindo segurança e desenvolvimento (condições de vida), são as seguintes:

a) as doenças devidas à miséria matam muito mais que as guerras. A miséria econômica e a insalubridade são, portanto, a principal ameaça à segurança humana. Como se diz no Parecer da Comissão de Segurança Humana de 2003: "mais de 800.000 pessoas perdem a vida anualmente vítimas da violência. Aproximadamente 2.800 milhões se sentem afetadas pela pobreza, saúde precária, analfabetismo e numerosas doenças"; 
15 milhões de pessoas morrem de fome por ano $^{49}$. O conflito e a privação são ligados entre si. A privação tem muitos vínculos ligados à violência, ainda que esses vínculos devam ser analisados cuidadosamente.

b) a cooperação é mais fácil na luta contra as doenças que na luta contra a violência; lutando contra aquelas, luta-se também contra essa ${ }^{50,51}$.

Esse enfoque amplo de segurança humana exige ao menos três mudanças relacionadas entre si e que afetam a cultura, a economia e a política.

No campo cultural, requer-se a mudança do paradigma epistemológico: daquele baseado na disjuntiva e na exclusão, por outro fundado na complementaridade dos opostos que elimine a unilateralidade ideológica de qualquer tipo, e que consinta recolher tudo o que possa atentar à segurança humana. Isso impõe considerar todas as mortes humanas evitáveis como violência inadmissível e principal causa de maior violência; exige ainda priorizar a prevenção de perigos dos mais vulneráveis, como as crianças nascidas ou simplesmente concebidas, doentes, anciãos, destinando a eles os recursos que seriam destinados aos militares. Seriam evitados assim os riscos derivados de uma utilização do conceito de segurança humana somente para defendermo-nos das hipotéticas ameaças alheias, e isso serviria como tomada de consciência da possível arbitrariedade de nosso estilo de vida ${ }^{52}$.

No campo econômico, esse conceito amplo, ao não limitar a segurança à ausência de violência, incluindo aí a exigência de luta contra a miséria, "favorece uma análise segundo a qual a insegurança seria resultado das estruturas de poder existentes, baseadas no crescimento econômico, sem satisfação das necessidades" ${ }^{33,54}$.

Esse enfoque amplo de segurança humana guarda relação também com a perspectiva do filósofo do direito Thomas Pogge, em sua tese sobre a responsabilidade dos países do Norte na perpetuação das injustiças globais, especialmente permitindo a governos nãodemocráticos a transferência de recursos naturais não-renováveis, concedendo créditos, cujo pagamento tardio provoca a miséria e pobreza do povo ${ }^{55}$.

A segurança humana requer distinguir entre a economia de mercado (que, como meio de designação de recursos, parece inevitável), e a antropologia do capitalismo, que propugna a primazia do ter sobre o $\operatorname{ser}^{56}$, e pela venalidade do ser humano, segundo a qual tudo estaria à venda, e os seres humanos se distinguiriam entre inteligentes e néscios (segundo se vendessem caro ou barato), e dementes, que seriam aqueles que não se considerassem à venda.

No campo político, o conceito de segurança humana é algo que surge com o desaparecimento da Guerra
Fria e se apoia na consciência de que os problemas planetários requerem uma abordagem que supere a contraposição entre "nós" e "eles". Essa superação da contraposição "nós"-“eles” não é nada fácil. A solidariedade com os próximos e afins é espontânea, enquanto que a solidariedade com os que estão afastados e que são diferentes requer maior reflexão e esforço. Por isso, hoje em dia resulta urgente chegar à consciência da identidade planetária, que não exclui as identidades particulares, mas antes as integra e complementa ${ }^{57}$.

Por último, como assinalaram Sharbanou Tadjbakhsh e Anuradha M. Chenoy, em seu livro "Human security: concepts and implications"58, seguindo a Ul-Haq e A. Sen, o sentido amplo de segurança humana, devido a sua conexão com a dimensão de desenvolvimento e com os direitos de segunda geração, ajuda a superar o relativismo cultural, uma vez que essas perspectivas dos direitos são as mais valoradas desde os países asiáticos e os países de maioria islâmica e, deste modo, a segurança humana contribui para ir compreendendo melhor a verdadeira universalidade dos direitos humanos ${ }^{59}$.

\section{REFERÊNCIAS}

ALKIRE, Sabina. A conceptual Framework for Human Security. In: CRISE Working Paper 2, Centre for Research on Inequality, Human Security and Ethnicity, Queen Elisabeth House, University of Oxford, 2003.

ANAND, Sudhir; SEN, Amartya. Human Development and Economic Sustainability. World Development, v. 28, n. 12, 2000, p. 2029-2049.

ANASSOVA-CORNELIS, Elena. Japan and the Human security Debate. History, Norms and Pro-active Foreign Police. Graduate Journal of Asia-Pacific Studies, 3:2 (2005), p. 58-72.

BALLESTEROS, Jesús. Identidad planetaria y medio ambiente. AAVV. Sociedad y medio ambiente. Madrid: Trotta, 1997. p. 227-247.

BALLESTEROS, Jesús. Sobre el sentido del derecho. 3. ed. Madrid: Tecnos, 2007.

BISCH, M. Le corps des droits de l'homme: l'indivisibilité comme principe d'interprétation et de mise en œuvre des droits de l'homme. Fribourg: Editions Universitaires, 1992.

FERNÁNDEZ PEREIRA, J. P. La seguridad humana. Barcelona: Ariel, 2006.

FERNÁNDEZ RUIZ GÁLVEZ, Encarnación. Derechos humanos, ¿yuxtaposición o integración?. Anuario de Filosofía del Derecho, 1996-97, p. 679-702.

FERRERO-WALDNER, B. Understanding human rights. Wien: Verlags GMBH, 2003.

GARGARELLA, R. Las teorías de la justicia después de Rawls. Barcelona: Paidós, 1999.

GASPER, Des. Securing Humanity. Situating the Human security discourse. Conference on the Capability Approach, University of Pavia, 2004.

HAYDEN, Patrick. Human Rights in Rawls's Law of Peoples. In: AAVV. Omaggio a Rawls, Quaderni della Rivista Internazionale di Filosofia del Diritto, coord. A. Punzi, n. 4, Milão, Giuffrè, 2004. 
KEIZO, Obuchi. Opening Remarks. The Asian Crisis and Human Security. Tóquio: Japan Center for International Exchange, 1999.

KING, Gary; MURRAY, Ch. Rethinking human security. Political Science Quarterly, v. 116, n. 4, 2002, p. 585-610.

LEAL MOYA, P. Seguridad humana. La responsabilidad de proteger. Boletín Mexicano de Derecho Comparado, n. 114, sept./ dic 2005, p. 1117-1138.

NUSSBAUM, Martha. Las fronteras de la justicia. Barcelona: Paidós, 2007.

ONU. Development Programme National Human Development Report Unit, maio 2006.

ORTIZ NAVARRETE, Jonathan. La doctrina de la seguridad humana en la política exterior canadiense. Revista CIDOB d'Afers Internacionals, 60, dicembre 2002 - gennaio 2003

PÉREZ DE ARMIÑO, Karlos. El concepto y el uso de la seguridad humana: análisis crítico de sus potencialidades y riesgos. Revista CIDOB d'Afers Internacionals, n. 76, 2007, p. $59-77$

PICADO SOTELA, Sonia. Seguridad humana y democracia en Centroamérica. San José de Costa Rica: Universidad para la Paz, 2003.

POGGE, Thomas. La pobreza en el mundo y los derechos humanos. Barcelona: Paidós, 2005.

RODILES, Alejandro. Coalitions of the willing, coyuntura, contexto y propiedades: Un primer esbozo. Anuario Mexicano de Derecho Internacional, 2007. v. VII, p. 675-702.
SEN, Amartya. Basic Education and Human Security. Workshop on Basic Education and Human Security. UNICEF, University of Kolkata, January 2002.

SEN, Amartya. Desarrollo y libertad. Barcelona: Planeta, 2000.

SEN, Amartya. Human rights and human security. SGI Quaterly (Human security now). July 2003, p. 09.

SOLER I LECHA, Eduard. Redimensionar el diálogo euromediterráneo en materia de seguridadel: el reto de la seguridad humana. Revista CIDOB d'Afers Internacionals, n. 76, 2007, p. 123-142.

ST. CLAIR, Asuncion. Ideas in Action: Capability as Boundary Concept between Knowledge and Politics. Enhancing Human Security, 5-7 September 2004, Università di Pavia.

ST. CLAIR, Asuncion. Poverty Conceptions in the UNDP and the World Bank: knowlegde, ethics and politics. Bergen Department of Sociology - University of Bergen, 2004.

TADJBAKHSH, Sharbanou; CHENOY, Anuradha M. Human security: concepts and implications. London, New York: Routledge, 2007.

THE WORLDWATCH INSTITUTE. Redefining the global security: The state of the world. 2005.

VIOLA, Francesco. La defensa de la persona en la era tecnológica. In: BALLESTEROS, J.; FERNÁNDEZ, E. (ed.). Biotecnologia y posthumanismo. Pamplona: Thomson-Aranzadi, 2007.

VIOLA, Francesco. L'etica dello sviluppo tra diritti de libertà e diritti social. In: VIOLA, F. Etica e metaetica dei diritti umani. Torino: Giappichelli, 2000.

WUST, P. Ungewissheit und Wagnis. München: Ketner, 1937.

\section{NOTAS}

1 Versão original do texto em língua espanhola: BALLESTEROS, Jesús. Seguridad humana, derechos y políticas públicas. Retos de la Justicia Global, Encuentro Mediterráneo de Jóvenes juristas, Foro Javea de Vecindad, 2009, p. 53-59. Versão publicada em italiano: BALLESTEROS, Jesús. Sicurezza umana e indivisibilità dei diritti. Ragion Pratica, n. 1, fasc. 30, 2008, p. 13-26.

2 O prof. Jesús Ballesteros Llompart é professor catedrático de Filosofia do Direito na Universitat de València, na Espanha. Autor de inúmeras publicações na Europa e na América, tanto em livros, artigos em revistas científicas e capítulos de livros - tratando de temas de filosofia e de filosofia do Direito, mas também e particularmente sobre questões propriamente pós-modernas, como: ecologismo personalista, direitos humanos, defesa de cultura de paz (e contra a violência), bioética, biodireito, secularismo, neofeminismo (feminismo de complementaridade). Informações sobre o autor no site: $<$ http://dialnet.unirioja.es/servlet/autor?codigo=519212>. E-mail: <Jesus.Ballesteros@uv.es>.

3 Sobre isso: ORTIZ NAVARRETE, Jonathan. La doctrina de la seguridad humana en la política exterior canadiense. Revista CIDOB d'Afers Internacionals, 60, dicembre 2002 - gennaio 2003, p. 50.

4 Sobre as diversidades das coalitions of the willing, ver: RODILES, Alejandro. Coalitions of the willing, coyuntura, contexto y propiedades: Un primer esbozo. Anuario Mexicano de Derecho Internacional, vol. VII, 2007, p. 675-702 (Nota de tradução: nota presente somente no original em espanhol, não constando na publicação em italiano).

5 ONU. Development Programme National Human Development Report Unit, maio 2006

6 Sobre isso: LEAL MOYA, P. Seguridad humana. La responsabilidad de proteger. Boletín Mexicano de Derecho Comparado, n. 114, sept-dic 2005, p. 1117-1138.

7 Nota de tradução: toda essa última frase do parágrafo se encontra somente no original em espanhol.

8 Nota de tradução: a expressão "em favor do desenvolvimento sustentável" nesta frase somente se encontra no original em espanhol.

9 Nota de tradução: a expressão que colocamos entre parênteses na frase consta na versão espanhola do texto, como uma alternativa ao que está na versão italiana, a qual foi adotada nesta tradução para constar no início da mesma frase do texto em português.

${ }^{10}$ Nota de tradução: a expressão que colocamos entre parênteses somente se encontra na versão espanhola do texto.

${ }^{11}$ Em seu artigo: GASPER, Des. Securing Humanity. Situating the Human security discourse. Conference on the Capability Approach, University of Pavia, 2004, p. 17

12 Nota de tradução: esse texto citado do autor Des Gasper atualmente se encontra disponível na Internet no seguinte site: $<\mathrm{http}: / / \mathrm{www}-3$ unipv.it/deontica/ca2004/papers/gasper.pdf $>$. Ademais, há uma versão impressa do autor na mesma linha: GASPER, Des. Securing Humanity: Situating ‘Human Security' as Concept and Discourse. Journal of Human Development and Capabilities, 2005, v. 6, issue 2, p. 221-245. Na versão impressa deste artigo de Jesús Ballesteros em italiano, em rodapé, consta o texto de St. Clair: ST. CLAIR, A. Poverty Conceptions in the UNDP and the World Bank: knowlegde, ethics and politics. Bergen Department of Sociology - University of Bergen (Norway), 2004.

${ }^{13}$ Nota de tradução: esta expressão entre vírgulas, falando do "Parecer sobre o Desenvolvimento Humano", somente se encontra na versão espanhola do texto.

${ }^{14}$ Sobre isso: SEN, A. Desarrollo y libertad. Barcelona: Planeta, 2000. p. 118.

15 Ver: SEN, A. Basic Education and Human Security. Workshop on Basic Education and Human Security. UNICEF, University of Kolkata, January 2002.

${ }^{16}$ Em: GASPER, Securing Humanity, 2004, cit. p. 12

17 Nota de tradução: na versão impressa em italiano, aparece a menção ao livro de St. Clair - ST. CLAIR, A. op. cit.

${ }_{18}$ Nota de tradução: na versão em espanhol do texto, o termo aparece em inglês, como colocamos no presente texto; o autor optou por fazer a tradução na versão em italiano.

19 Nota de tradução: optou-se por fazer uma adaptação do texto em português às versões consultadas, em que se quis demonstrar por enfoques diferentes em uma e outra, o lado positivo e o negativo da vida humana. 
${ }^{20}$ Essa fragilidade é distinta da fragilidade ética, consubstancial ao homem enquanto ser contingente necessitado de valores transcendentes (WUST, P. Ungewissheit und Wagnis. München: Ketner, 1937; VIOLA, F. La defensa de la persona en la era tecnológica. In: BALLESTEROS, J.; FERNÁNDEZ, E. (ed.). Biotecnología y posthumanismo. Pamplona: Thomson-Aranzadi, 2007. p. 58).

${ }^{21}$ Nota de tradução: a expressão que se encontra entre vírgulas nesta frase está somente na versão espanhola deste texto, ressaltando os conflitos entre Estados. Na versão italiana, ressaltam-se os conflitos internos.

${ }^{22}$ É significativo que os dois países que são os principais defensores da doutrina da segurança humana, Japão e Canadá, sejam, por sua vez, os aliados da União Europeia no G8 na exigência da luta contra a mudança climática, frente às posições de Estados Unidos e Rússia, partidários de um industrialismo incontrolado.

${ }^{23}$ KEIZO, Obuchi. Opening Remarks. The Asian Crisis and Human Security. Tóquio: Japan Center for International Exchange, 1999.

${ }^{24}$ Nota de tradução: há um comentário do prof. Ballesteros com relação à citação anterior, constando somente em nota de rodapé da versão espanhola do texto - Sobre a proposta japonesa de segurança humana, ver: ANASSOVA-CORNELIS, Elena. Japan and the Human security Debate. History, Norms and Pro-active Foreign Police. Graduate Journal of Asia-Pacific Studies, 3:2 (2005), p. 58-72.

${ }_{25}$ Nota de tradução: essa primeira frase da citação corrente que o prof. Ballesteros faz no parágrafo somente aparece na versão espanhola do texto.

${ }^{26}$ Sobre isso: THE WORLDWATCH INSTITUTE. Redefining the global security: The state of the world. 2005. p. 106 et seq.

${ }^{27}$ Nota de tradução: na versão italiana do texto é citada a obra - FERREROWALDNER, B. Understanding human rights. Wien: Verlags Gmbh, 2003. p. 18. Há uma versão disponível na Internet, em que se fala disto (nas p. 16-17): <http://www.etc-graz.at/typo3/fileadmin/user upload/ ETC-Hauptseite/manual/versionen/modules_eng/Manual\%20komplett. pdfs.

${ }^{28}$ Ver o artigo: KING, Gary; MURRAY, Ch. Rethinking human security. Political Science Quarterly, vol. 116, n. 4, 2002, p. 585-610.

${ }_{29}$ PICADO SOTELA, Sonia. Seguridad humana y democracia en Centroamérica. San José de Costa Rica: Universidad para la Paz, 2003. p. 40.

${ }^{30}$ SEN, A. Human rights and human security. SGI Quaterly (Human security now). July 2003, p. 09.

${ }_{11}$ Nota de tradução: está disponível na Internet em versão $\mathrm{html}$ a entrevista citada em nota anterior de Amartya Sen $-<\mathrm{http}$ ://www.sgiquarterly.org/ feature2003Jly-1.html>.

${ }^{32}$ Em seu artigo: ALKIRE, Sabina. A conceptual Framework for Human Security. In: CRISE Working Paper 2, Centre for Research on Inequality, Human Security and Ethnicity, Queen Elisabeth House, University of Oxford, 2003

33 Nota de tradução: o texto de Sabina Alkire mencionado na citação anterior está disponível na Internet no seguinte site $-<\mathrm{http}: / /$ economics. ouls.ox.ac.uk/13003/1/workingpaper2.pdf>.

${ }^{34}$ PICADO SOTELA, Seguridad humana y democracia en Centroamérica, cit., p. 40.

35 Ultimamente, no seu livro: NUSSBAUM, M. Las fronteras de la justicia. Barcelona: Paidós, 2007.

${ }^{36}$ Em seu artigo: VIOLA, F. L'etica dello sviluppo tra diritti de libertà e diritti social. In: VIOLA. Etica e metaetica dei diritti umani. Torino: Giappichelli, 2000. p. 82 et seq.

37 Ver: BISCH, M. Le corps des droits de l'homme: l'indivisibilité comme principe d'interprétation et de mise en œuvre des droits de l'homme. Fribourg: Editions Universitaires, 1992.

38 Ver: FERNÁNDEZ RUIZ GÁLVEZ, E. Derechos humanos, ¿yuxtaposición o integración?. Anuario de Filosofía del Derecho, 1996-97, p. $679-702$.
39 Ver: ANAND, Sudhir; SEN, Amartya. Human Development and Economic Sustainability. World Development, vol. 28, n. 12, 2000, p. 2029-2049.

40 Nota de tradução: o conceito de "capabilities" de Amartya Sen é utilizado pelo prof. Ballesteros na versão italiana do texto normalmente em inglês, diferentemente do que ocorre na versão espanhola, sempre traduzindo a expressão.

${ }^{41}$ Nisso coincidem Mackinnon, Dworkin e Cohen, segundo: GARGARELlA, R. Las teorías de la justicia después de Rawls. Barcelona: Paidós, 1999.

${ }^{42}$ Para a crítica às insuficiências dos urgent rights de Rawls, ver, entre outros: HAYDEN, Patrick. Human Rights in Rawls's Law of Peoples. In: AAVV. Omaggio a Rawls, Quaderni della Rivista Internazionale di Filosofia del Diritto, coord. A. Punzi, n. 4, Milão, Giuffrè, 2004.

${ }^{43}$ Ver: THOMAS, Caroline. Global Governance. Development and Human security. The Challenge of Poverty and Inequalities. London: Pluto Press, 2000, apud FERNÁNDEZ PEREIRA, J. P. La seguridad humana. Barcelona: Ariel, 2006. p. 91.

${ }^{44}$ Nota de tradução: esta frase se encontra somente na versão espanhola do texto, no mesmo local.

${ }^{45}$ Nota de tradução: a expressão que se encontra entre parênteses corresponde ao que o autor colocou no texto em espanhol, de forma alternativa ao que está no texto em italiano e que traduzimos antes dos parênteses.

${ }^{46}$ Ver: ALKIRE, A conceptual Framework for Human Security, cit. p. 40.

${ }^{47}$ Nota de tradução: esta frase somente existe no original publicado em italiano.

${ }^{48}$ Nota de tradução: esta expressão "relativismo cultural" não existe no título da seção do texto em italiano; somente no texto espanhol.

${ }^{49}$ ALKIRE, A conceptual Framework for Human Security, cit. p. 28.

50 Ver: SOLER I LECHA, E. Redimensionar el diálogo euromediterráneo en materia de seguridadel: el reto de la seguridad humana. Revista CIDOB d'Afers Internacionals, n. 76, 2007, p. 138.

51 Nota de tradução: está disponível na Internet o artigo citado de Eduard Soler i Lecha, comentando sobre esse tema nas pág. 138 e $139-<\mathrm{http} / /$ dialnet.unirioja.es/servlet $/$ articulo? codigo $=2288263>$.

${ }^{52}$ Em favor do enfoque amplo da segurança humana, manifestaramse, entre outros: Duffield, Krause, Pérez de Armiño, Alkire, Bajpai, Hampson, G. King e Ch. Murray, Thakur, etc.

53 PÉREZ DE ARMIÑO, K. El concepto y el uso de la seguridad humana: análisis crítico de sus potencialidades y riesgos. Revista CIDOB d'Afers Internacionals, n. 76, 2007, p. 75.

${ }^{54}$ Nota de tradução: o texto de Karlos Pérez de Armiño citado em nota anterior se encontra disponível na Internet $-<$ http://dialnet.unirioja.es/ servlet $/$ articulo? $\operatorname{codigo}=2288238>$.

55 Ver: POGGE, Thomas. La pobreza en el mundo y los derechos humanos. Barcelona: Paidós, 2005. Ver também ST. CLAIR, Asuncion. Ideas in Action: Capability as Boundary Concept between Knowledge and Politics. Enhancing Human Security, 5-7 September 2004, Università di Pavia.

56 Nota de tradução: esta expressão entre vírgulas (da primazia do ter sobre o ser) se encontra somente na versão espanhola do texto.

57 Sobre a identidade planetária, remeto a meu artigo: BALLESTEROS, J. Identidad planetaria y medio ambiente. AAVV. Sociedad y medio ambiente. Madrid: Trotta, 1997. p. 227-247; e a meu livro: BALLESTEROS, Jesús. Sobre el sentido del derecho. 3. ed. Madrid: Tecnos, 2007. p. 110 et seq.

58 Ver: TADJBAKHSH, Sharbanou; CHENOY, Anuradha M. Human security: concepts and implications. London, New York: Routledge, 2007. p. 136 et seq.

${ }^{59}$ Nota de tradução: o presente parágrafo no texto somente se encontra na versão espanhola consultada. 